\title{
Alaska Mountain Wilderness Ski Classic: Alterations in Caloric Expenditure and Body Composition
}

\author{
Michelle M. Johannsen, MS; Kenneth J. Shin, BS; Karolina Priebe, DNP; Robert H. Coker, PhD \\ From the Institute of Arctic Biology, University of Alaska, Fairbanks, Fairbanks, AK (Ms Johannsen, Mr Shin, and Dr Coker); and the Mountain \\ View Medical Center, Fairbanks, AK (Dr Priebe).
}

\begin{abstract}
Introduction-The Alaska Mountain Wilderness Ski Classic is a self-supported ultramarathon crosscountry skiing event that traverses one of the mountain ranges of Alaska each winter. Unique aspects of this event challenge athletes with a significant amount of physical and mental stress while in the chronically cold conditions of the Arctic. Assessment of energy requirements or body composition has never been performed during this event. The objective of the study was to evaluate the influence of the 2016 Alaska Mountain Wilderness Ski Classic on caloric expenditure and body composition.

Methods-Caloric expenditure was estimated using GT3x+ Actigraph accelerometers and ActiLife software. Lean tissue mass, total fat mass, visceral fat mass, and bone mineral density were measured using a General Electric iDXA before and after the event. Data are presented as mean \pm SD. Differences were analyzed using paired $t$ tests with significance at $P<0.05$.

Results-Fifteen participants (age $=32.7 \pm 6.6$ years, body mass index $=23.7 \pm 2.3 \mathrm{~kg} \cdot \mathrm{m}^{2}$ ) completed

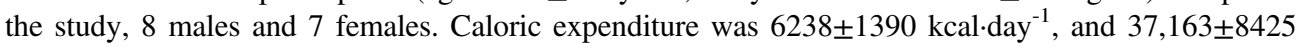
$\mathrm{kcal}$ for the entire event. Fat mass was reduced from pre-event $(\Delta 1.3 \pm 0.7 \mathrm{~kg}, P=0.00003)$. There was an increase in lean tissue mass $(\Delta 1.7 \pm 1.3 \mathrm{~kg}, P=0.0003)$ and relative skeletal muscle index $(\Delta 0.2 \pm 0.2$ $\left.\mathrm{kg} \cdot \mathrm{m}^{2}, P=0.001\right)$. There was no change in bone mineral density $\left(\Delta 0 \pm 0 \mathrm{~g} \cdot \mathrm{cm}^{3}, P=0.4\right)$.

Conclusions-Despite the metabolic demands, fat mass was reduced and lean tissue mass was preserved. Future studies of this event should be directed toward assessment of the nutritional provisions utilized and the mechanisms responsible for the preservation of lean tissue mass.
\end{abstract}

Keywords: endurance, cold exposure, fat mass, lean tissue mass, physiological resilience, arctic

\section{Introduction}

The Alaska Mountain Wilderness Ski Classic (AMWSC) was founded in 1987 and is recognized as one of the most challenging backcountry treks available to crosscountry skiers. ${ }^{1}$ The course changes every 3 years and can be 160-289 km (100-180 mi) long, traversing one of the Alaskan mountain ranges. Because these mountain ranges exhibit seasonal changes at different times, the date of the AMWSC varies depending on the location. The event is most often held in the month of April,

Corresponding author: Michelle M. Johannsen, MS, Institute of Arctic Biology, University of Alaska - Fairbanks, 2090 Koyukuk Drive, Fairbanks, AK 99775-7000; e-mail: mmjohannsen@alaska.edu.

Submitted for publication June 2017.

Accepted for publication February 2018.

Data collected from this study were presented at the Northwest American College of Sports Medicine annual meeting, February 15, 2017, Bend, OR; and the National American College of Sports Medicine meeting, June 1, 2017, Denver, CO. during the late winter-early spring season, when temperatures range from -20 to $-12^{\circ} \mathrm{C}$.

Unlike many ultramarathon events, the AMWSC is entirely self-supported. Participants must carry all food, equipment, and medical/first aid supplies that might be needed during the event. The participants are permitted to consume foods of their choosing ad libitum throughout the event. There are no aid stations, and it is the responsibility of the participant to establish an expected return date with friends or family and devise a plan of action if rescue becomes necessary. In previous years, courses of a similar length took participants 5 to 7 days to complete. Communications in this region are severely limited, but participants may carry a satellite phone or a global positioning system SOS messenger system. Reliance on these devices as a safety net during the event is not recommended, given that electronics do not function well at low temperatures and that mountain ranges often interfere with communication signaling. Participants are 
not retrieved from the course by event personnel. Instead, if they have not arrived at the finish line or reported that they have dropped out to fellow competitors by an 8-day cutoff time, an emergency contact and the Alaska State Troopers would be called.

The 2016 AMWSC took place in the Brooks Range, the northernmost mountain range of Alaska. The course started at Galbraith Lake, above the Arctic Circle, sandwiched between the Arctic National Wildlife Refuge to the east and the Gates of the Arctic National Park and Preserve to the west. The participants traveled approximately $289 \mathrm{~km}(180 \mathrm{mi})$, moving southwest from the lake to Anaktuvuk Pass in the Gates of the Arctic National Park, then traveling southeast and ending in Wiseman, Alaska, at the southern edge of the Brooks Range. In the 2016 AMWSC, 31 individuals participated (20 males, 11 females), but only 15 individuals participated in the study described herein. All participants were required to complete a mandatory check-in at the halfway point of the event at the National Park Service Office at Anaktuvuk Pass.

The AMWSC is a physically and mentally challenging event, yet energy requirements and alterations in body composition have never been measured. The duration and intensity of exercise and harsh environmental exposure in an event like this may create special alterations in body composition. ${ }^{2,3}$ For example, exercising in the cold may promote a significant reduction in fat mass (FM) but mitigate deleterious alterations in lean tissue mass (LM). ${ }^{4,5}$ Similar conclusions have been drawn from studies of athletes participating in the 692km (430-mi) Yukon Arctic Ultra, during which temperatures can frequently reach below $-40^{\circ} \mathrm{C} .{ }^{6}$

The purpose of the present study was to estimate caloric expenditure and measure changes in body composition elicited by prolonged exercise under chronic cold exposure in athletes participating in the AMWSC. We hypothesized that LM would be preserved in athletes participating in the AWMSC.

\section{Methods}

After consultation with the organizers of the event, research participants were recruited from athletes registered in the 2016 AMWSC event. Study participants arrived at the University of Alaska Fairbanks (UAF) Clinical Research and Imaging Facility within $48 \mathrm{~h}$ of the start and end the event for all measurements. This study was approved by the UAF Institutional Review Board.

Data were analyzed using Microsoft Excel, ActiLife, and iDXA software. Data are presented as mean \pm SD for all metrics. Paired $t$ tests were used to compare differences between pre-event and post-event values and differences between male and female values. Statistics were considered significant with a $P$ value of $<0.05$.

\section{MEASUREMENT OF BODY COMPOSITION}

Body composition was measured using dual energy xray absorptiometry scans (General Electric-Lunar iDXA, Chicago, IL). The scans measured LM, FM, relative skeletal muscle index, bone mineral density, and visceral adipose tissue using enCORE software (General Electric Healthcare, Chicago, IL). Bodyweight was also measured using a digital scale (Seca 769; Seca, Chino, CA) before and after the event during the same visits.

\section{ESTIMATION OF CALORIC EXPENDITURE}

Participants were outfitted with GT3X+ ActiGraph accelerometers (ActiGraph Corp, Pensacola, FL) worn around the wrist for the entire duration of the event. These monitors were programmed to begin recording movement at the start of the event and were turned off by the researchers after the participants had completed the event. Data were interpreted using the ActiLife software and the "Freedson 1998 algorithm" to calculate estimated caloric expenditure. ${ }^{7}$ This algorithm does not account for the additional energy required to carry a load. Therefore, the following equation was used to account for additional caloric expenditure of carrying a pack:

caloric expenditure/ $\mathrm{h} \times[$ (pack weight + body weight $) /$ (body weight) $]=$ total caloric expenditure/h

We developed this equation by entering body weight into the Actigraph software and then the combined body weight and pack weight to determine the coefficient by which caloric expenditure increased when each participant was carrying a load. Coincidentally, this coefficient was approximately equal to the ratio of combined body and pack weight to body weight alone.

Participants self-reported their backpack weights and kilocalories consumed during the event. Initial pack weights averaged $16 \pm 3 \mathrm{~kg}(37 \pm 6 \mathrm{lb})$ with an approximate but not directly measured $1 \mathrm{~kg}(2 \mathrm{lb})$ reduction in pack weight for each day of the event to account for the consumption of daily meals. The ratio of combined body and pack weight to body weight alone was recalculated for each day of the event to account for the daily $1 \mathrm{~kg}$ reduction in pack weight. Because participants would remove their backpacks during periods of rest and sleep, the equation used for the estimation of caloric expenditure was only implemented during times when the individual's activity was above a threshold value of an 
Table 1. Body composition changes at pre- and post-event.

\begin{tabular}{|c|c|c|c|c|c|c|}
\hline & $\begin{array}{c}\text { Pre-event } \\
\text { (male) }\end{array}$ & $\begin{array}{c}\text { Post-event } \\
\text { (male) }\end{array}$ & $\begin{array}{c}\text { Pre-event } \\
\text { (female) }\end{array}$ & $\begin{array}{l}\text { Post-event } \\
\text { (female) }\end{array}$ & $\begin{array}{c}\text { Pre-event (all } \\
\text { participants) }\end{array}$ & $\begin{array}{c}\text { Post-event (all } \\
\text { participants) }\end{array}$ \\
\hline Total LM (kg) & $66 \pm 4$ & $68 \pm 3^{a}$ & $50 \pm 4^{b}$ & $51 \pm 3^{b}$ & $59 \pm 9^{a}$ & $61 \pm 9^{a}$ \\
\hline Total FM (kg) & $12 \pm 4$ & $10 \pm 3^{a}$ & $12 \pm 3$ & $11 \pm 2^{a}$ & $12 \pm 3$ & $11 \pm 3^{a}$ \\
\hline Percent fat $(\%)$ & $15 \pm 4$ & $13 \pm 4^{a}$ & $20 \pm 3^{b}$ & $11 \pm 2^{a, b}$ & $17 \pm 4$ & $15 \pm 4^{a}$ \\
\hline $\operatorname{RSMI}\left(\mathrm{kg} \cdot \mathrm{m}^{2}\right)$ & $10 \pm 1$ & $10 \pm 1^{a}$ & $78 \pm 1^{b}$ & $8 \pm 1^{a, b}$ & $9 \pm 1$ & $9 \pm 1^{a}$ \\
\hline $\operatorname{BMD}\left(\mathrm{g} \cdot \mathrm{cm}^{3}\right)$ & $1 \pm 0$ & $1 \pm 0$ & $1 \pm 0$ & $1 \pm 0$ & $1 \pm 0$ & $1 \pm 0$ \\
\hline VAT mass (g) & $364 \pm 130$ & $301 \pm 156$ & $89 \pm 55^{b}$ & $122 \pm 103$ & $246 \pm 184$ & $224 \pm 160^{a}$ \\
\hline VAT volume $\left(\mathrm{cm}^{3}\right)$ & $386 \pm 138$ & $319 \pm 165$ & $95 \pm 58^{b}$ & $130 \pm 109$ & $261 \pm 184$ & $238 \pm 170^{a}$ \\
\hline
\end{tabular}

LM, lean tissue mass; FM, fat mass; RSMI, relative skeletal muscle index; BMD, bone mass density; VAT, visceral adipose tissue.

All data are presented as mean \pm SD.

${ }^{a}$ Significant difference compared with pre-event $(P<0.05)$.

${ }^{b}$ Significant difference compared with male $(P<0.05)$.

estimated $50 \mathrm{kcal} \cdot \mathrm{h}^{-1}$. At this threshold, they were presumed to be traveling along the course and therefore carrying the backpack.

\section{Results}

\section{BODY COMPOSITION}

There were 15 participants who completed the study: 8 males and 7 females $(n=15$; age $=32.7 \pm 6.6$ years; Table 1). There was a significant reduction in FM from pre-event values for all participants $(\Delta-1.3 \pm 0.8 \mathrm{~kg}$; $P=0.001)$. On the contrary, LM $(\Delta 1.7 \pm 1.3 \mathrm{~kg}$, $P=0.0001)$ and the relative skeletal mass index $\left(\Delta 0.2 \pm 0.2 \mathrm{~kg} \cdot \mathrm{m}^{2}, P=0.001\right)$ were increased from preevent values. There was no change in bone mass density
$\left(\Delta 0 \pm 0 \mathrm{~g} \cdot \mathrm{cm}^{3}\right)$. VAT was not reduced from pre-event to postevent $(\Delta$ mass $=-22 \pm 100 \mathrm{~g}, P=0.4 ; \Delta$ volume $=-23$ $\left.\pm 107 \mathrm{~cm}^{3}, P=0.4\right)$. There were no significant differences in age or BMI between males and females $(\mathrm{BMI}=24.3$ \pm 2.4 and $23.2 \pm 2.1 \mathrm{~kg} \cdot \mathrm{m}^{2}$, respectively). Percent FM was different between men and women both before (14.8 $\pm 4.0 \%$ and $19.5 \pm 2.8 \%$, respectively; $P=0.02$ ) and after the event $(12.8 \pm 3.5 \%$ and $17.8 \pm 2.7 \%$, respectively; $P=0.006$ ). However, the percent of FM lost from preevent to postevent did not differ between the sexes (men: $1.5 \pm 1.0 \%$; women: $1.0 \pm 0.5$ ).

\section{CALORIC EXPENDITURE}

Data for days 1 to 5 represent means from all 15 participants. Day 6 represents the remaining 5 males

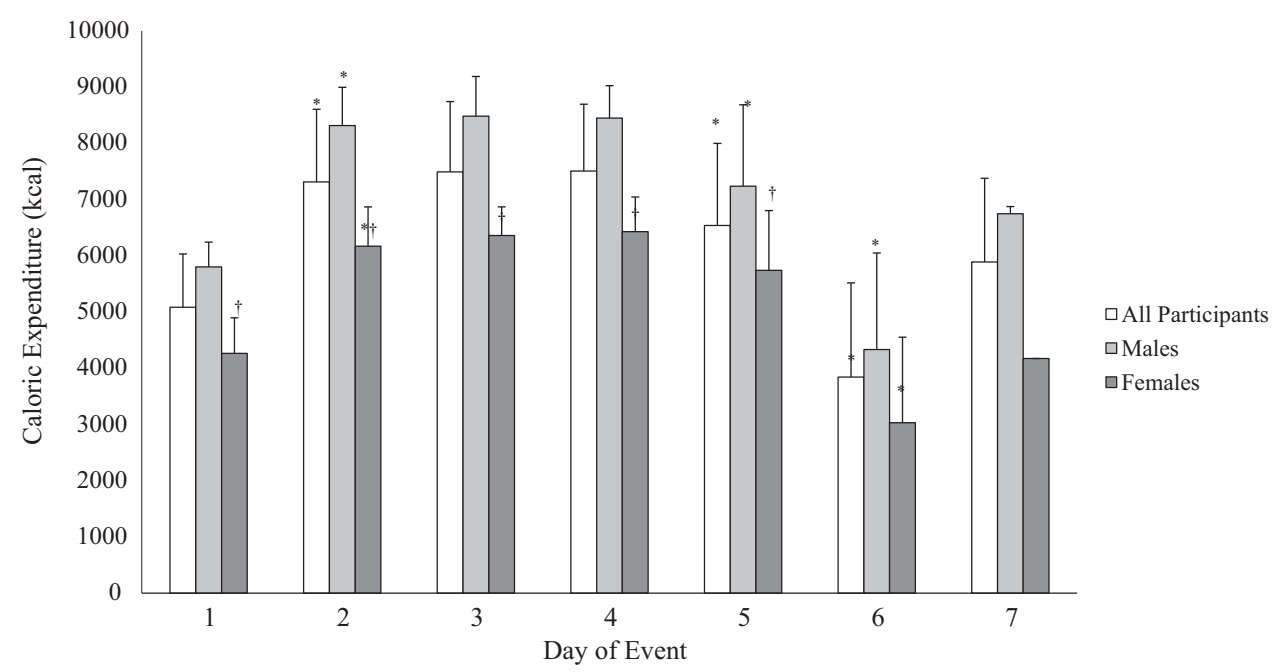

Figure 1. Estimated daily caloric expenditure \pm SD for all participants and sexes for each day of the event. Because of different finishing times, days 1-5 represent all participants. Day 6 represents the remaining 5 males and 3 females. Day 7 represents the remaining 2 males and single

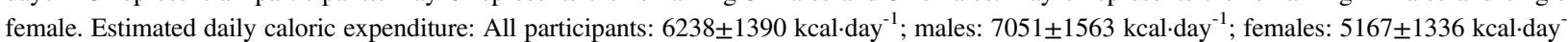
1. * Significant compared with previous day, $P<0.05$. 'Significant compared with males for that day, $P<0.05$. 
and 3 females. Day 7 represents the remaining 2 males and single female (Figure 1). Participants provided general information regarding dietary intake, such as an estimated $4000 \mathrm{kcal} \cdot \mathrm{day}^{-1}$, but did not detail the macronutrient profile of their diet. The estimated caloric expenditure of all participants was $6238 \pm 1390 \mathrm{kcal} \cdot \mathrm{day}^{-1}$ and $37,163 \pm 8425 \mathrm{kcal}$ for the entire event (Figure 1). Estimated caloric expenditure for each day and for the duration of the event was significantly different between men and women (Figure 1; $P=0.03$ and $P=0.002$, daily and total event, respectively). Pack weights relative to body mass used in the calculation of caloric expenditure were significantly higher in women, by about $5 \%$ compared with men (ie, $21 \pm 2 \%$ and $26 \pm 5 \%$ of body mass for men and women, respectively). Time to complete the event did not differ between men $(125.0 \pm 20.1 \mathrm{~h})$ and women $(119.3 \pm 18.0 \mathrm{~h})$.

\section{Discussion}

We hypothesized that the combined stress of prolonged physical activity and chronic cold exposure during the AMWSC would promote a reduction in FM but preserve LM. Consistent with our hypothesis, all participants either maintained or gained LM and lost a significant amount of FM (Table 1). With an estimated caloric expenditure of $\sim 37,000 \mathrm{kcal} \cdot \mathrm{event}^{-1}\left(6238 \pm 1390 \mathrm{kcal} \cdot \mathrm{day}^{-1}\right.$ and an estimated caloric intake of $\sim 4000 \mathrm{kcal} \cdot \mathrm{day}^{-1}$ ), this might seem somewhat surprising. The results of the present study and previous work in ultramarathon athletes during the Yukon Arctic Ultra support the retention of LM during arduous physical stress combined with extreme cold, ${ }^{5}$ but the mechanisms responsible are not entirely clear. In addition to the potential influence of cold exposure on hepatokines, myokines, and adiopkines, which may influence metabolism, ${ }^{6}$ previous studies have also found that increased protein intake promotes the retention of LM in context of caloric deficiency initiated by physical activity and inadequate dietary kcal intake. ${ }^{7}$

Our estimation of caloric expenditure was lower in the female participants (Figure 1), but their completion time was not different from the males. Given the smaller body mass of women, the lower caloric expenditure for this event was anticipated. However, women were carrying a proportionately larger load than men. It is possible that women may have some sort of work efficiency advantage under these conditions compared with men. The results of this study do not lend insights into the mechanism of this observation, which warrants further investigation.

\section{LIMITATIONS}

The method for estimating caloric expenditure was a significant limitation of the present study. Algorithms used to translate vector magnitudes into caloric expenditure estimates from ActiGraph monitors do not exist for cross-country skiing. ${ }^{8}$ Utilization of doubly labeled water would have provided more accurate measurements of caloric expenditure for this event than accelerometer data. ${ }^{9}$ Doubly labeled water uses an isotopic form of water that is heavier than normal water to track the turnover/production of water due to energy metabolism. This method was not available for the present study.

The interpretation of our data related to caloric expenditure and macronutrient intake is also limited by the lack of specific information related to dietary intake. Athletes disclosed that they ate as much as they could relative to the constraints of time, physical activity, and sleep requirements. Due to the importance of protein intake in preserving $\mathrm{LM}^{7}$ future studies should closely examine the role of macronutrient intake. Daily pack weight reductions and energy/food consumption were based on self-reported values by the participants, rather than weighing the packs or obtaining data from dietary recall methods. This could have led to an overestimation in our caloric expenditure calculations.

The remote nature of the event also complicated the assessment of body composition. These measurements were taken at the Clinical Research and Imaging Facility at the UAF within $48 \mathrm{~h}$ of the start and end of the event. It is possible that during this time, participants may have recovered a small amount of LM or FM that may have been lost during the event. In addition, LM, as measured by dual energy $\mathrm{x}$-ray absorptiometry scans, includes anything that is not bone or FM, such as organ tissue. Direct determination of skeletal muscle mass via magnetic resonance imaging and/or isotopic approaches would have provided more specific information on alterations in body composition. ${ }^{10}$ The isotope technique only requires a small urine sample from the participant and would overcome the confounding effects of a delayed measurement due to the commute between the event and the laboratory $(\sim 570 \mathrm{~km}$ and $\sim 12 \mathrm{~h}$ by road) by collecting urine at the event itself.

\section{Conclusions}

We hypothesized that LM would be preserved despite sustained high levels of caloric expenditure and chronic cold exposure under self-supported conditions in the 2016 AMWSC. In agreement with previous studies, our results demonstrated that LM was indeed preserved, despite substantial caloric expenditure. ${ }^{3-5}$ As an ancillary finding, sex differences in work efficiency may exist, and our results warrant further investigation. Future studies should be directed toward a greater understanding of the 
nutritional provisions utilized and the mechanisms behind the preservation of LM under sustained physical activity and extreme cold conditions.

Acknowledgments: We thank the AMWSC organizers and the athletes for participating in this research project, and to Dave Cramer, President of the AMWSC organization and event coordinator.

Author Contributions: Study concept and design (RHC); obtaining funding (RHC); acquisition of the data (KS, KP, RHC); analysis of the data (MJ, KS, RHC); drafting of the manuscript (MJ, KS, RHC); critical revision of the manuscript (RHC); approval of final manuscript (RHC).

Financial/Material Support: Research reported in this publication was supported by an Institutional Development Award (IDeA) from the National Institute of General Medical Sciences of the National Institutes of Health under grant number P20GM103395. Travel funding was provided by BLaST to attend the ACSM conferences where this study was presented. The content is solely responsibility of the authors and does not necessarily reflect the official views of the NIH.

Disclosures: Dr. Robert Coker is a managing partner and co-owner of Essential Blends, LLC, which has received funding from the National Institutes of Health to develop clinical nutrition products. The data presented in this manuscript are unrelated.

\section{References}

1. Summit Consulting Services Inc website. Alaska Mountain Wilderness Ski Classic. Available at: http://www.scsa laska.com/ski/. Accessed November 15, 2017.
2. Bircher S, Enggist A, Jehle T, Knechtle B. Effects of an extreme endurance race on energy balance and body composition-a case study. J Sports Sci Med. 2006;5(1): 154-62.

3. Knechtle B, Bircher S. Changes in body composition during an extreme endurance run. Praxis (Bern 1994). 2005;94(10):371-7.

4. O'Hara W, Allen C, Shephard R. Loss of body weight and fat during exercise in a cold chamber. Eur J Appl Physiol Occup Physiol. 1977;37(3):205-18.

5. O'Hara W, Allen C, Shephard R. Treatment of obesity by exercise in the cold. Can Med Assoc J. 1977;117(7):773-8.

6. Coker R, Weaver A, Coker M, Murphy C, Gunga H, Steinach M. Metabolic responses to the Yukon Arctic Ultra. Med Sci Sports Exerc. 2017;49(2):357-62.

7. Mettler S, Mitchell N, Tipton KD. Increased protein intake reduces lean body mass loss during weight loss in athletes. Med Sci Sports Exerc. 2010;42(2):326-37.

8. Trost S, McIver K, Pate R. Conducting accelerometerbased activity assessments in field-based research. Med Sci Sports Exerc. 2005;37(suppl):S531-43.

9. Sjödin A, Anderson A, Höberg J, Westerterp K. Energy balance in cross-country skiers: a study using doubly labeled water. Med Sci Sports Exerc. 1994;26(6):720-4.

10. Clark C, Walker A, O'Connor-Semmes R, Leonard MS, Miller RR, Stimpson SA, et al. Total body skeletal muscle mass: estimation by creatine $\left(\right.$ methyl $-\mathrm{d}_{3}$ ) dilution in humans. J Appl Phyiol. 2014;116(12):1605-13. 